\title{
Lipolytic Activity of Human Cutaneous Bacteria
}

\author{
By R. F. SMITH AND N. P. WILLETT \\ Department of Microbiology, Temple University School of Pharmacy \\ Philadelphia, Pa., U.S.A.
}

(Accepted for publication 20 February 1968)

\begin{abstract}
SUMMARY
Forty-two strains of Corynebacterium acnes were compared with 20 strains of staphylococci and Io of lipophilic diphtheroids for their lipolytic action on I4 substrates and for Tween 80 hydrolysis. All strains were isolated from normal human skin. One lipophilic diphtheroid and 33 C. acnes strains hydrolysed tributyrin. Forty-nine bacillary strains hydrolysed Tween 80 . None of the other substrates was degraded. C. xerosis ATCC 373 and Propionibacterium acnes ATCC II828 acted on tributyrin. $P$. acnes also hydrolysed Tween 80 . The staphylococci did not act on Tween 80 but attacked tributyrin, triolein, trilinolenin, trilinolein and oil emulsions. Some cocci acted on tricaprylin, tricaprin and trilaurin; no lipolysis by this group was observed of trimyristin, tripalmitin or tristearin. Pancreatic lipase, tested by the penicylinder diffusion method for comparison, was active on the same substrates, as were the cocci. The addition of glucose, lactate and urea to media did not inhibit lipolysis by the cocci. Sodium oleate inhibited pancreatic lipase action on triolein and cottonseed oil but not on the hydrolysis of tributyrin. Coccal lipase action was not inhibited by oleate. All 74 test strains were uniformly inhibited by neomycin 5-10 $\mu \mathrm{g}$. $/ \mathrm{ml}$. Grampositive cocci rather than $C$. acnes appear primarily responsible for bacterial lipase activity on human skin.
\end{abstract}

\section{INTRODUCTION}

Previous studies indicate that the predominant microbial flora of normal human skin consists of only three groups of bacteria. These include the staphylococci and micrococci, facultative diphtheroids, many of which are lipophilic, and Corynebacterium acnes (Marples, 1965). Indirect evidence suggests that cutaneous bacteria are partially responsible for lipase action on skin, causing the release of fatty acids from the hydrolysis of sebum or triglycerides (Strauss \& Mescon, 1959). Staphylococci and micrococci produce lipases and many strains hydrolyse polyoxyethylene sorbitan compounds such as Tween 80 (Baird-Parker, 1963). C. acnes hydrolyses Tween 80 (Brzin, 1965) and has been reported to act on tributyrin (Puhvel, 1967). Little is known about $C$. acnes action on other lipids or the possible effects of lipophilic diphtheroids on tributyrin or similar substrates. To gain more information about the lipolytic activity of the skin flora, studies were made to compare lipolysis by $C$. acnes strains with other human skin bacteria. 


\section{METHODS}

Organisms. Cotton-wool swabs were moistened in sterile saline and rubbed over an area of about $4 \times 4 \mathrm{~cm}$. of the faces or forearms of normal human adults; these swabs were discarded. A second swab was rubbed over the same area, placed in $10 \mathrm{ml}$. sterile saline, and mixed for $30 \mathrm{sec}$. with an automatic tube shaker. The excess saline was pressed out of the swab into the tube and the swab removed. This saline suspension was used for plating experiments and streaking on the following media: Mannitol salt and Staphylococcus I IO agars (Baltimore Biological Laboratories), Veillonella agar (Difco) and $5 \%$ sheep blood agar with heart infusion base (Difco). One set of these plates was incubated aerobically at $35^{\circ}$ for 5 days. A second set including only Veillonella and blood agars was incubated anaerobically in Brewer jars with Gaspaks (BBL) and placed at $35^{\circ}$ for 5-7 days. Gram-positive cocci were isolated from mannitol salt or I Io agars. Strains were transferred in brain heart infusion broth (BHI), restreaked on either selective medium and re-isolated. Cocci were characterized by using the methods of Baird-Parker (1963). Facultative diphtheroids were isolated from blood agar. Isolates of this group were identified by Gram reaction and provisionally as lipophilic strains by their greater growth in BHI broth containing sodium oleate or Tween 80 (Pollock, Wainwright \& Mansion, 1949). Efforts to classify this group were attempted by using standard procedures (Manual of Microbiological Methods, 1957). Corynebacterium acnes strains were isolated from anaerobically incubated plates. They were identified by using current information on the diagnostic characteristics of this organism (Prevot, 1966) and confirmed by agglutination by using the methods and antisera for $C$. acnes of the National Communicable Disease Center, Atlanta, Georgia, U.S.A. Cocci and diphtheroids were maintained on slopes of heart infusion agar containing $0.1 \%$ yeast extract, $0.2 \%$ glucose and $0.2 \%$ Tween 80 . C. acnes strains were maintained in thioglycollate medium (BBL). Propionibacterium acnes ATCC II828 and C. xerosis ATCC 373 were included in the study for comparison.

Measurement of lipolysis. Lipolytic activity was detected by using Spirit blue agar (Difco). Triglycerides (Sigma Chem. Co., St Louis, Mo.), corn oil, olive oil, cholesterol and cottonseed oil (Proflo oil, Traders Oil Mill Co., Fort Worth, Texas) were prepared as $20 \%(\mathrm{w} / \mathrm{v})$ emulsions with a $2.5 \%$ sterile solution of gum acacia. Oil emulsions were autoclaved at $118^{\circ}$ for $10 \mathrm{~min}$; triglyceride emulsions were sterilized by flowing steam. Substrates were incorporated into the medium in final concentrations of $0.6 \%(\mathrm{v} / \mathrm{v})$. Cocci and diphtheroid plates were incubated for 2-5 days. Corynebacterium acnes plates were incubated in Brewer jars for 7-8 days. Lipolysis was indicated by clearing of the emulsions. Strains which were negative or weakly positive were examined under a dissecting microscope for evidence of lysis under or at the edge of the colonies.

A crude pancreatic lipase (Nutritional Biochem. Corp., Cleveland, Ohio) was prepared as a $\mathrm{r} \%$ aqueous suspension $(\mathrm{pH} 8 \cdot 0)$ and tested for its activity on the test substrates by filling penicylinders placed in the centre of each plate, and incubated overnight at 35 degrees. On removal of the cylinders, areas of lipolysis were usually 8-10 $\mathrm{mm}$. in diameter.

In later experiments, certain compounds were incorporated into Spirit blue agar to measure their effects on the lipase activity of the bacterial isolates. These compounds 
included glucose, sodium lactate, sodium oleate and urea which were sterilized separately by filtration and added to melted media at $46^{\circ}$.

Strains were tested for neomycin sensitivity in the medium of Schultz-Haudt \& Scherp (1956). Neomycin solutions were sterilized by filtration. Growth of the strains was measured in a Spectronic 20 colorimeter (Bausch and Lomb). Tween 80 hydrolysis was measured by the method of Wayne (1962).

\section{RESULTS}

The Gram-positive cocci were classified as group 2 staphylococci. The lipophilic diphtheroids were Gram-positive catalase-producing bacilli which consistently grew in palisade forms. Glucose and sodium pyruvate were fermented; maltose, sucrose, fructose, mannitol and lactose were not fermented. These strains were also negative in the following tests: urease and indole production, nitrate reduction, gelatin liquefaction, action on litmus milk and motility. Growth occurred in broths containing $6.5 \%$ and $7.5 \% \mathrm{NaCl}$ and feebly in $15 \% \mathrm{NaCl}$ broth. One strain produced a brown pigment; the other strains were non-pigmented. These strains were tentatively considered related to the Corynebacteriaceae because of their morphology and salt tolerance (Bergey's Manual, 1957).

Table I. Lipolytic activity of selected strains of the predominant human cutaneous flora

\begin{tabular}{|c|c|c|c|c|}
\hline \multirow[b]{2}{*}{ Substrate } & \multicolumn{4}{|c|}{ Group tested } \\
\hline & \multicolumn{2}{|c|}{$\begin{array}{c}\text { Lipophilic } \\
\text { Staphylococci diphtheroids }\end{array}$} & $\begin{array}{c}\text { Coryne- } \\
\text { bacterium } \\
\text { acnes }\end{array}$ & $\begin{array}{c}\text { Pancreatic } \\
\text { lipase }\end{array}$ \\
\hline & \multicolumn{3}{|c|}{ Number of positive strains } & \\
\hline Tributyrin & 20 & $\mathbf{I}$ & 33 & + \\
\hline Tricaprylin & IO & 0 & 0 & + \\
\hline Tricaprin & IO & 0 & 0 & + \\
\hline Trilaurin & 10 & 0 & 0 & + \\
\hline Trimyristin & 0 & 0 & 0 & - \\
\hline Tripalmitin & 0 & 0 & 0 & - \\
\hline Tristearin & 0 & 0 & 0 & - \\
\hline Triolein & 20 & 0 & 0 & + \\
\hline Trilinolein & 19 & 0 & 0 & + \\
\hline Trilinolenin & 19 & o & 0 & + \\
\hline Olive oil & 19 & 0 & 0 & + \\
\hline Cholesterol & 0 & 0 & 0 & - \\
\hline Cottonseed oil (Proflo) & 19 & 0 & 0 & + \\
\hline Corn oil & 19 & 0 & 0 & + \\
\hline Tween 80 hydrolysis & 0 & 9 & 40 & $n t^{*}$ \\
\hline Total strains tested & 20 & I0 & 42 & \\
\hline
\end{tabular}

Forty-two strains of Corynebacterium acnes were compared with 20 staphylococci and 1o lipophilic diphtheroids for their lipolytic action on I4 lipid substrates and for Tween 80 hydrolysis (Table I). One lipophilic diphtheroid and $33 \mathrm{C}$. acnes strains hydrolysed tributyrin and 40 strains hydrolysed Tween 80 . None of the other substrates was attacked by these two groups. C. xerosis ATCC 373 and Propioni- 
bacterium acnes ATCC Ir 828 acted on tributyrin. Propionibacterium acnes hydrolysed Tween 8o. The Grarn-positive cocci acted on tributyrin, triolein, trilinolein, trilinolenin and the oil emulsions; only half of the staphylococci attacked tricaprylin, tricaprin and trilaurin and no action was observed by this group on trimyristin, tripalmitin or tristearin. Repeated tests with these three compounds at $0.1 \%$ concentrations were negative. Tween 80 was not hydrolysed by the cocci. Pancreatic lipase was active on the same substrates as the lipase-producing cocci.

Lipolytic activity of the cutaneous cocci was also shown by enumerating this group in plating experiments (Table 2). Colony counts of lipolytic bacteria on Spirit blue agar were almost identical to those on mannitol salt agar. Lipolytic colonies from both Spirit blue media showed only Gram-positive cocci; similar results were obtained incubating the plates anaerobically. Lipophilic diphtheroids and Corynebacterium acnes were not routinely found among the nonlipolytic colonies developing on Spirit blue media.

Table 2. Enumeration of the major lipolytic bacteria on human skin

\begin{tabular}{lc}
\multicolumn{1}{c}{ Medium } & Colony counts/sample* \\
Total & 126,000 \\
Mannitol salt agar & 85,000 \\
Spirit Blue agar & \\
+ Tributyrin & 85,000 \\
+ Cottonseed oil & 83,000
\end{tabular}

* Counts based on facial swab of $16 \mathrm{~cm} .^{2}$ area diluted in sterile saline. Plates were incubated aerobically 5 days at $35^{\circ}$. Total count medium consisted of heart infusion agar with $0.2 \%$ glucose, $0.2 \%$ Tween 80 and $0.1 \%$ yeast extract. Only lipase forming colonies were counted on Spirit Blue agar.

The cocci and pancreatic lipase were retested for lipase action on tributyrin, triolein and cottonseed oil. The following compounds were separately added to

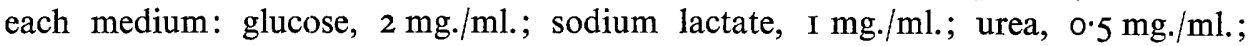
sodium oleate, $304 \mu \mathrm{g} . / \mathrm{ml}$. (this is equal to a final concentration of $\mathrm{I} \mu \mathrm{M}$ ). Sodium oleate inhibited pancreatic lipase action on triolein and cottonseed oil but not on tributyrin. The other compounds were not inhibitory to pancreatic lipase. The lipolytic action of the cocci was not inhibited by any of the added compounds.

The incorporation of neomycin sulphate $5-10 \mu \mathrm{g} . / \mathrm{ml}$. to broth or agar media inhibited the growth of all strains.

\section{DISCUSSION}

Gram-positive cocci appear to be the only major cutaneous bacteria with appreciable lipase activity. These results provide evidence that Corynebacterium acnes is not one of the predominant lipolytic bacteria of skin. Inhibition of bacterial lipase in tissue sections treated with neomycin spray (Strauss \& Mescon, 1959) is more likely to be due to inhibition of coccal growth and not $C$. acnes growth or activity.

Glucose has been reported to suppress microbial lipase formation (Smith \& Alfords, I966) but the glucose concentration used in our test medium did not prevent the action of the lipolytic cocci. Lactate and urea, which are excreted in large quantities by the skin (Marples, 1965) were also inactive as lipase inhibitors. Certain lipases are known to be inhibited by a concentration of $\mu$ M-oleate (Smith \& Alford, I966). 
This was observed by using pancreatic lipase with a cylinder diffusion method. The accumulation of oleic acid on skin would not appear to inhibit staphylococcal lipase activity. The continued recognition of new lipids secreted by skin (Kellum, 1967a, $b$ ) may indicate that many more substrates are available for bacteria to act upon. Corynebacterium acnes, which resides primarily in the pilosebaceous units of the skin (Marples, 1965) might act differently in response to certain yet unidentified lipids. The $\mathrm{C}_{18}$ unsaturated triglycerides were hydrolysed while failure of the cocci and the pancreatic lipase to act upon trimyristin, tripalmitin and tristearin may be a function of chain length and saturation of the compounds. Variations in qualitative determinations of lipase activity has been reported (Muys \& Willemse, 1965). Spirit blue agar was generally satisfactory for this comparative study.

\section{REFERENCES}

BAIRD-PARKer, A. C. (1963). A classification of micrococci and staphylococci based on physiological and biochemical tests. J. gen. Microbiol. 30, 409.

Bergey's Manual of Determinative Bacteriology. (1957). 7th ed. Ed. by R. S. Breed, E. G. D. Murray \& N. R. Smith. Baltimore: Williams and Wilkins.

BrzIN, B. (1965). Comparative studies on anaerobic corynebacteria and actinomycetes. Acta path. microbiol. scand. 63, 415 .

Kellum, R. E. (1967a). Human sebaceous gland lipids. Arch. Dermatol. 95, 218.

Kellum, R. E. $(1967 b)$. Short chain fatty acids (below $\mathrm{C}_{12}$ ) of human skin surface lipids. J. invest. Dermatol. 48, 364 .

Manual of Microbiological Methods. (1957). Society of American Bacteriologists. New York: McGrawHill.

Marples, M. S. (1965). The Ecology of the Human Skin. Springfield, Ill.: C. C. Thomas.

MuYS, G. T. \& WILLEMSE, R. (I965). The detection and enumeration of lipolytic micro-organisms by means of a modified Eykman-plate method. Antonie van Leeuwenhoek. 31, 103.

Pollock, M. R., WaInwright, S. D. \& Mansion, E. D. (1949). The presence of oleic acid requiring diphtheroids on human skin. J. Path. Bact. 6r, 274.

PRÉvot, A. R. (1966). Manual for the Classification and Determination of the Anaerobic Bacteria. Philadelphia: Lea and Febiger.

Punvel, M. (1967). Characterization of Corynebacterium acnes. Bact. Proc. p. 78.

Schultz-Haudt, S. D. \& SCHeRP, H. W. (1956). The production of chondro-sulfatase by microorganisms isolated from human gingival crevices. J. dent. Res. 36, 299.

Sмith, J. L. \& Alford, J. A. (1966). Inhibition of microbial lipases by fatty acids. Appl. Microbiol. I4, 699 .

Strauss, J. S. \& Mescon, H. (1959). The chemical determination of specific lipases in comedones. J. invest. Dermatol. 35, $19 \mathrm{I}$.

Wayne, L. G. (1962). Differentiation of mycobacteria by their effect on Tween 80. Am. Rev. resp. Dis. 86, 579, 